\title{
Selection and Characterization of Potential Baker's Yeast from Indigenous Resources of Nepal
}

\author{
Tika B. Karki, ${ }_{1}$ Parash Mani Timilsina, ${ }^{1}$ Archana Yadav, ${ }^{1}$ Gyanu Raj Pandey, ${ }^{1,2}$ \\ Yogesh Joshi, ${ }^{1}$ Sahansila Bhujel, ${ }^{1}$ Rojina Adhikari, ${ }^{1}$ and Katyayanee Neupane ${ }^{1}$ \\ ${ }^{1}$ Department of Biotechnology, Kathmandu University, Dhulikhel, Nepal \\ ${ }^{2}$ Biotechnological Research and Development Center Pvt., Ltd., Bharatpur, Nepal \\ Correspondence should be addressed to Tika B. Karki; ktika@ku.edu.np
}

Received 12 July 2017; Accepted 20 November 2017; Published 13 December 2017

Academic Editor: Yau Hung Chen

Copyright (C) 2017 Tika B. Karki et al. This is an open access article distributed under the Creative Commons Attribution License, which permits unrestricted use, distribution, and reproduction in any medium, provided the original work is properly cited.

The study aims to isolate the yeast strains that could be used effectively as baker's yeast and compare them with the commercial baker's yeast available in the market of Nepal. A total of 10 samples including locally available sources like fruits, Murcha, and a local tree "Dar" were collected from different localities of Bhaktapur, Kavre, and Syangja districts of Nepal, respectively. Following enrichment and fermentation of the samples, 26 yeast strains were isolated using selective medium Wallerstein Laboratory Nutrient Agar. From the differential tests which included morphological and microscopic observation and physiological and biochemical characterization such as nitrate reduction and lactose utilization tests, 8 strains were selected as possible Saccharomyces strain. The selected strains were further assessed for their efficient leavening ability by tests such as ethanol tolerance, osmotolerance, invertase test, and stress exclusion test. The three most potent strains ENG, MUR3B, and SUG1 isolated from grape, Murcha, and sugarcane, respectively, were used in the fermentation and baking of dough. These strains also carried a possibility of being used as industrial baker's yeast.

\section{Introduction}

Saccharomyces cerevisiae, the microorganism used in baking industry as a leavening agent [1], with the advancements in bread industry, has been continuously improvised for decades [2]. The main yeast strain is commonly reported to be responsible for alcoholic fermentation [3]. This yeast utilizes the hexose sugars especially maltose to produce $\mathrm{CO} 2$, ethanol, and variety of secondary metabolites such as esters, aldehydes, and amino acids that contribute to the development of flavor and aroma of the fermented food $[4,5]$. The carbon dioxide thus produced is responsible for not only increasing the volume of dough (leavening process) through gas incorporation but also a value addition to the flavor and texture [6]. Besides, the fermentation products like vitamins and amino acids are responsible for the health and nutritional benefits that are obtained from bread [7].

Yeast exists in natural environment like plant tissues, fruits, grains, leaves, dung, soil, and other fermented products [8]. The best source of yeast is considered to be citrus juice
[9] and sugarcane juice [10]. Yeast strains present on fruit surfaces are able to ferment variety of sugars to alcohol and can withstand high alcohol concentration.

Although the consumption of baker's yeasts in Nepal is rising every year, the country imports its entire requirement of baker's yeast mostly from China and Europe. Nepal imports the baker's yeast of 10 million US dollar worth in 2013 [11]. Nepal, being a country with wide diversity of flora and fauna, has a high possibility of inhabiting unique strains of baker's yeast which is yet to be explored. Considering the economic importance of yeasts in baking industries of Nepal, the following study was done to isolate potential baker's yeast strains with leavening properties from various local sources. Different physiological properties of yeast such as invertase activity, flocculation, ethanol tolerance, hyperosmotic tolerance, temperature tolerance, and $\mathrm{CO}_{2}$ production for a strain to be used as a commercial baker's were also analyzed $[12,13]$.

Boehmeria rugulosa, commonly known as Dar or Githais, an indigenous tree grown in Nepal from 300 to $1700 \mathrm{~m}$, is most common in the higher elevation Shorea robusta forests 
and in Alnus nepalensis forests at about $1500 \mathrm{~m}$ [14]. The bark is dark brown in color and very rough and deep fissures render it into small, more or less rectangular scales [15]. People in Parroha VDC, Rupandehi, mix a paste or powder of Boehmeria rugulosa bark with rice flour to prepare Sel-Roti, typical Nepali ring bread generally used during festivals [16]. Since the members of Saccharomycetales are also present in the bark of certain deciduous trees [17], there is a possibility that the bark of Dar may contain some Saccharomyces species.

Murcha is a mixed starter culture which contains mixture of fermenting yeasts, saccharifying molds and acidifying bacteria [18], which is used as an inoculum for making local alcohol (jand) in Himalayan regions of Nepal, India, Bhutan, and Tibet $[19,20]$. Murcha is a round cake which is mildly acidic with $\mathrm{pH}$ about 5.2 [21]. It is traditionally prepared from wild plants that harbor microorganisms needed for the amylolytic fermentation (Rai and Subba (2003)).

\section{Materials and Methods}

2.1. Materials. Ten samples which include 6 fruit samples, that is, sugarcane (Saccharum officinarum), apple (Malus domestica), grapes (Vitis vinifera), jackfruit (Artocarpus heterophyllus), mango (Mangifera indica), and papaya (Carica papaya), soil, Murcha, bark of "Dar" (Boehmeria rugulosa), and commercial active dry yeast powder as reference were collected. The samples were aseptically stored at $4^{\circ} \mathrm{C}$.

2.2. Isolation and Preservation of Yeast Colonies [22, 23]. Enrichment was done to increase the number of native microflora present in the sample by adding $27 \%(\mathrm{w} / \mathrm{v})$ sucrose in the crushed fruit samples and was allowed to ferment for 3 days. The prepared samples were plated on Wallerstein Laboratory Nutrient Agar medium supplemented with chloramphenicol (0.01\%) at $\mathrm{pH} 5.5$ and allowed to grow for 72 hours. Through morphological examination, two distinct yeast colonies, that is, white and green, were selected. The selected colonies were subsequently subcultured on Yeast Malt (YM) Agar medium supplemented with chloramphenicol $(0.01 \%)$ to obtain pure isolates.

Maltose is the principle carbon source during bread fermentation. Thus, baker's yeast strains are good utilizers of maltose [24]. The presence of maltose as the primary sugar source in YM media and final pH set to $4.6 \pm 0.1$ (optimum $\mathrm{pH}$ for Saccharomyces strain) also act as screen as it enhances the growth of baker's yeast.

2.3. Microscopic Observation. A single colony of yeast was mixed in a droplet of sterile distilled water on glass slide and smeared until the smear dried off. The smear was then stained using diluted lactophenol cotton blue dye, air-dried, and observed under light microscope at 100x magnification.

\subsection{Screening}

2.4.1. Nitrate Reduction Test [25-27]. A well isolated colony was inoculated in nitrate broth (peptone $10 \mathrm{~g}, \mathrm{KNO} 310 \mathrm{~g}$ in $1000 \mathrm{ml}$ distilled water). It was incubated at $30^{\circ} \mathrm{C}$ for 48 hours. After incubation, 5 drops of both reactive 1 ( $\alpha$-naphthylamine
$1 \mathrm{~g}$, distilled water $22 \mathrm{ml}$, heat solution, filter, and then adding acetic acid $1 \mathrm{ml}$ ) and reactive 2 (sulphanilic acid $0.5 \mathrm{~g}$, diluted acetic acid $150 \mathrm{ml}$ ) was added in the tube. The appearance of red color was observed after 5-10 minutes.

2.4.2. Lactose Utilization Test [28]. Yeast cells were grown at $30^{\circ} \mathrm{C}$ for 3 days into Yeast Fermentation Broth (YFB) (peptone $7.5 \mathrm{~g} / \mathrm{L}$, yeast extract $4.5 \mathrm{~g} / \mathrm{L} ; 1 \mathrm{ml}$ of $1.6 \%(\mathrm{w} / \mathrm{v})$ bromothymol blue as an indicator) with autoclaved $6 \%(\mathrm{w} / \mathrm{v})$ lactose. The Durham tubes were also placed into the media to trap the carbon dioxide released. The changes from green to yellow indicated that yeast using the carbon source, that is, lactose.

2.4.3. Stress Exclusion Test [29]. In this test, the isolates were subsequently grown in different conditions that mimicked the various stresses. Firstly, the isolates were grown onto YPG medium and incubated at $30^{\circ} \mathrm{C}$ for 3 days. From that, a single colony was transferred and grown on YPG medium and incubated at $37^{\circ} \mathrm{C}$ for another 3 days. Again, a colony was selected and subcultured to YPG $8 \%(\mathrm{v} / \mathrm{v})$ ethanol and incubated at $30^{\circ} \mathrm{C}$ for 3 days. A single isolated colony was further subcultured on YPG supplemented with $20 \%(\mathrm{w} / \mathrm{v})$ glucose and incubated under the same conditions. Finally, yeast cells were transferred on YP medium supplemented with $2 \%(\mathrm{w} / \mathrm{v})$ sucrose and $8 \%(\mathrm{v} / \mathrm{v})$ ethanol and incubated under the same conditions.

2.4.4. Hydrogen Sulfide Test [30]. The yeast isolates were grown on lead acetate medium $(40 \mathrm{~g} / \mathrm{L}$ glucose, $5 \mathrm{~g} / \mathrm{L}$ yeast extract, $3 \mathrm{~g} / \mathrm{L}$ peptone, $0.2 \mathrm{~g} / \mathrm{L}$ ammonium sulphate, $1 \mathrm{~g} / \mathrm{L}$ lead acetate, and $20 \mathrm{~g} / \mathrm{L}$ agar) and incubated at $30^{\circ} \mathrm{C}$ for 7 days.

2.4.5. Flocculation Test. The yeast isolates were inoculated in $10 \mathrm{ml}$ of YPG broth and incubated at $30^{\circ} \mathrm{C}$ for 3 days. They were agitated to observe the flocculation forming.

2.4.6. Temperature Tolerance Test. Yeast isolates were cultured on YPG agar and incubated at $25^{\circ} \mathrm{C}, 30^{\circ} \mathrm{C}, 37^{\circ} \mathrm{C}$, and $45^{\circ} \mathrm{C}$ for $72 \mathrm{~h}$. Growth was observed and analyzed [29].

2.4.7. Carbohydrate Utilization Test [28]. The carbohydrate utilization test was performed using broth (peptone: $10 \mathrm{~g}$; $\mathrm{NaCl}: 5 \mathrm{~g}$; phenol red: $0.018 \mathrm{~g}$; distilled water: $1000 \mathrm{ml}$; carbohydrate: $10 \mathrm{~g}$ ) along with inverted Durham tubes in the broth. The carbohydrates used were dextrose, fructose, lactose, galactose, maltose, and sucrose. The media were inoculated with yeast strains and incubated for $24 \mathrm{hrs}$. The color change from red to yellow indicated the fermentation using carbon sources.

2.4.8. Hyperosmotic Tolerance Test. Yeast isolates were cultured on YPD broth containing 30, 40, and 50\% dextrose and incubated at $30^{\circ} \mathrm{C}$ for 48 hours. The cell density of different yeast isolates in response to high dextrose concentration was taken.

2.4.9. Ethanol Tolerance Test [29]. Yeast isolates were grown in YPG broth containing 3 different concentrations of ethanol, 
that is, $10 \%, 13 \%$, and $15 \%(\mathrm{v} / \mathrm{v})$, respectively, and incubated at $30^{\circ} \mathrm{C}$ for 72 hours.

2.4.10. Biomass Comparison in Different Sugars. YPD broth modified with respective sugars was used. Cell density of yeast isolates in sucrose and glucose media was compared. The cell density was measured using DEN-1B Grant bio Densitometer. 18 phi test tubes were used for generating data and data were obtained in McFarland standards.

\subsubsection{Invertase Activity Test}

(1) Enzyme Production. The media for the production of enzyme consist of the following $(\mathrm{g} / \mathrm{l})$ : sucrose 20 , yeast extract 10 , ammonium sulphate 1.0 , magnesium sulphate 0.75 , and potassium dihydrogen phosphate 3.5 with final $\mathrm{pH}$ 5. After inoculation with yeast strains, the media were incubated at $30^{\circ} \mathrm{C}$ in incubator shaker at $120 \mathrm{rpm}$ for 48 hours. After 48 hours, supernatant was harvested by centrifugation at $10000 \mathrm{rpm}$ for 10 minutes at $4^{\circ} \mathrm{C}$. This supernatant was used as crude enzyme extract.

(2) Enzyme Assay [31]. Slightly modified Sumner and Howells method was used for determining invertase activity. Enzymatic reaction was prepared by incubating $0.1 \mathrm{~mL}$ of enzyme solution with $0.9 \mathrm{~mL}$ of sucrose in $0.03 \mathrm{M}$ acetate buffer (pH 5.0) for 5 minutes at $30^{\circ} \mathrm{C}$. Reaction was stopped with addition of $1 \mathrm{ml}$ of dinitrosalicylic acid reagent and was heated in boiling water bath for 15 minutes. Finally, absorbance was taken at $540 \mathrm{~nm}$ in UV-1800 Shimadzu Spectrophotometer.

2.4.12. Cultivation and Dough Leavening. Cultivation of the yeast strains was done in conical flasks in $250 \mathrm{ml}$ media containing yeast extract, peptone, and sucrose. The flasks were kept in shaker incubator at $30^{\circ} \mathrm{C}$ for 72 hours and yeast pellets were collected after centrifugation at 10,000.

For each strain, 50-gram wheat flour was weighed and $1 \%$ salt was mixed with the flour. $6 \%$ sugar was dissolved in lukewarm water and $0.6 \mathrm{~g}$ yeast pellets were inoculated in the sugar solution to allow its activation. The activated yeast solution was poured in the flour and mixed well. The DY5 which is a commercial yeast strain was used as a positive control, whereas the dough without any yeast was used as a negative control. Proofing was done by incubating the dough at $30^{\circ} \mathrm{C}$ for 2 hours. It was then baked in hot air oven at $180^{\circ} \mathrm{C}$ for 20 minutes.

Besides, to assess the rise of dough level, about $10 \mathrm{~g}$ of dough mixture was kept in measuring cylinder. It was incubated and the level was noted every half hour.

\section{Results and Discussion}

The colonies exhibiting characteristics such as creamy to white color, fluffy, and smooth margin were selected as tentative Saccharomyces strain. As reported by Graeme and $\mathrm{Nia}$, in 2005, cream colonies are the characteristic of yeast especially Saccharomyces strain.

The isolation tests as described previously were used for identification of $S$. strain. Out of 26 selected tentative yeast
TABLE 1: Flocculation test.

\begin{tabular}{lccc}
\hline S. number & Samples & Flocculation & Hydrogen sulfide production \\
\hline$(1)$ & MUR3B & Yes & ++ \\
$(2)$ & ENG & Yes & + \\
$(3)$ & DPSW & Yes & -- \\
$(4)$ & FAPW & No & ++ \\
$(5)$ & DY5 (SC) & Yes & +++ \\
$(6)$ & SUG1 & Yes & + \\
$(7)$ & JAK3 & No & +++ \\
$(8)$ & SUGW & Yes & + \\
\hline
\end{tabular}

+++ : intensive response; ++: moderate response; +: low response; --: no response.

colonies, 14 showed negative lactose utilization result; that is, they were unable to utilize lactose and thus were possible Saccharomyces strains. S. cerevisiae can be identified due to its ability to ferment sucrose, maltose, fructose, glucose, galactose, and raffinose but not lactose (Thais et al., 2006) as the strain lacks lactase or $\beta$-galactosidase system [32]. In addition, 17 strains gave negative result in nitrate utilization test which means they were unable to utilize nitrate as sole source of carbon and could be considered as a possible Saccharomyces strain. The yeasts of the genera Saccharomyces and Schizosaccharomyces are unable to use nitrate or nitrite as sole nitrogen source [33]. From these two tests, 14 isolates were selected. The isolate DY5 was obtained from dry yeast sample from the local market to be used as a reference.

$S$. cerevisiae has a characteristic ellipsoid or ovoid shape [34]. AT 100x, the strains, which showed morphology similar to commercial yeast DY5, were oval in shape, and showed high budding rate, were selected (Figure 1). The strains ENG and MUR3B showed highest budding rate which indicates the higher growth rate and active fermentation as described previously [35].

Therefore, the screening of Saccharomyces spp. from the 30 isolates was done by studying the colony characteristics, cell morphology, and lactose utilization pattern and nitrate reduction test. Eight isolates were selected as final candidates for further biochemical tests. The final screened isolates were from Murcha (MUR3B), grape (ENG), Dar (DPSW), sugarcane (SUG1 and SUGW), apple (FAPW), jackfruit (JAK3), and the commercial strain (DY5).

All strains except JAK3 and FAPW showed flocculation property (Table 1). The strains exhibiting good flocculating ability are commercially beneficial as they are easier to separate from media without additional filtration and centrifugation steps during bulk production at industrial scale [36]. Yeast strains producing high levels of hydrogen sulfide are undesirable because $\mathrm{H}_{2} \mathrm{~S}$ imparts bad odor and flavor compromising the quality of the bread [37]. All the other strains were acceptable as baker's yeast as the standard commercial strain DY5 produced the highest amount of $\mathrm{H}_{2} \mathrm{~S}$ comparatively.

The viability of isolated strains was checked under spontaneous stress conditions such as temperature $37^{\circ} \mathrm{C}$, ethanol $8 \%$, sucrose $2 \%$, and glucose $20 \%$ for 15 days. It is necessary to check the capacity of baker's yeast to survive 


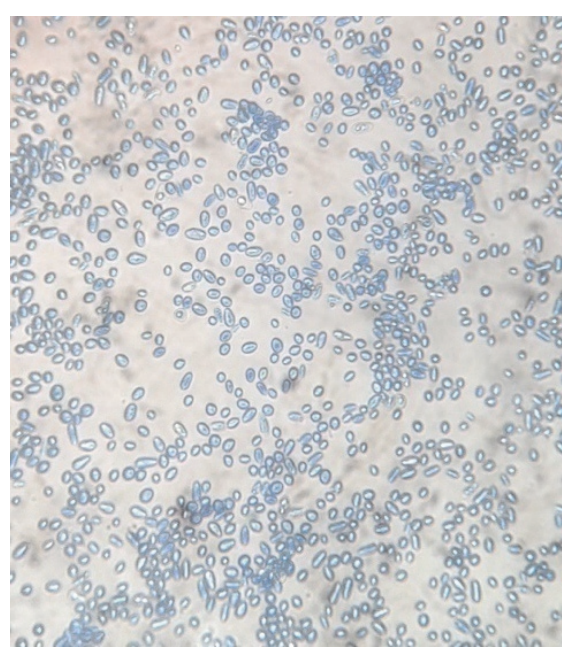

(a) DY5

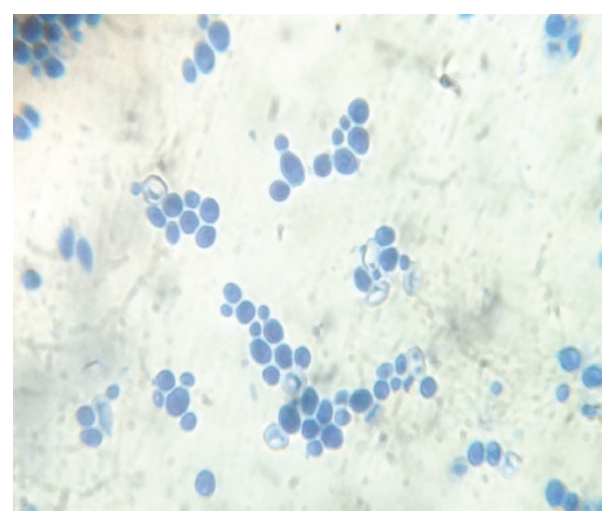

(d) MUR3B

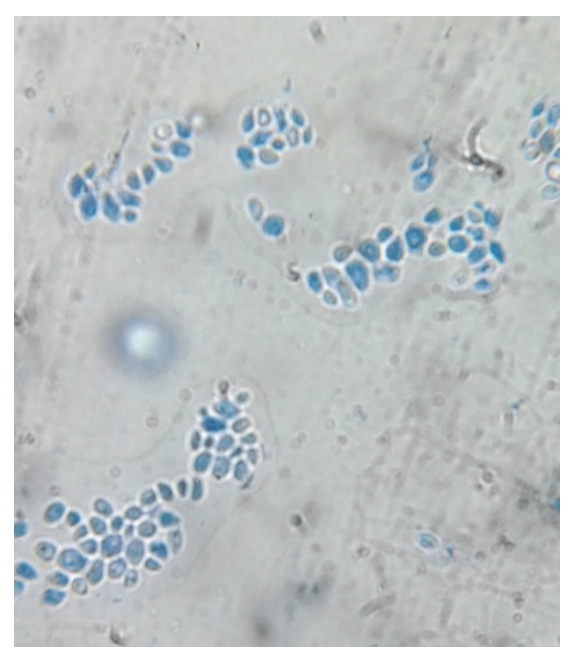

(b) FAPW

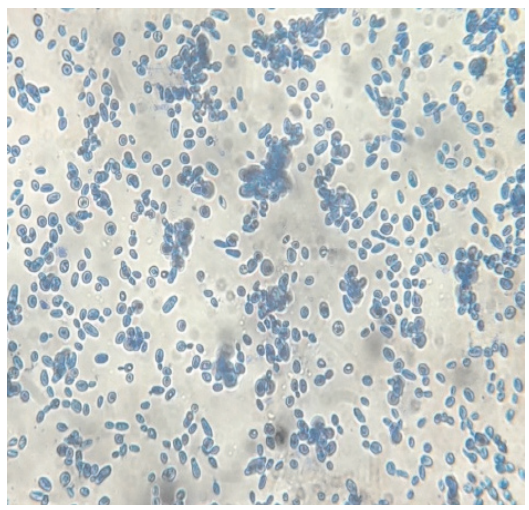

(e) ENG

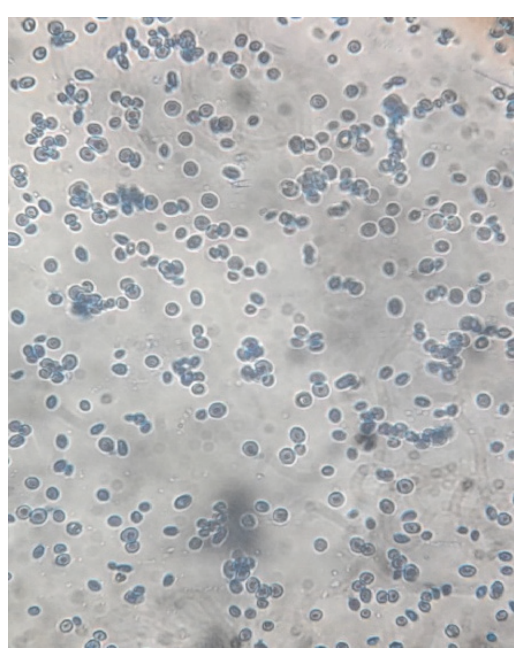

(c) SUG1

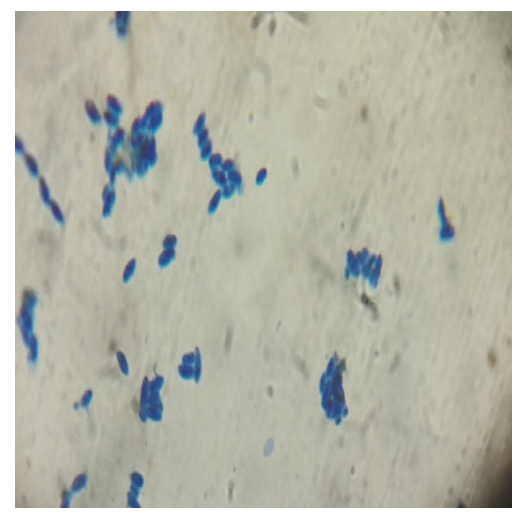

(f) DPSW

FIGURE 1: Microscopic observation of yeast colonies from different sources as observed at 100x magnification.

these stress conditions as they mimic the ethanol, osmotic, and temperature stress that yeast faces during baking. In the presence of these stresses, yeast becomes impaired and its survival denotes that yeast can carry out fermentation even in these harsh conditions $[38,39]$. Also, the last step of the test that checks the tolerance to sucrose may be an important indication of high invertase activity [40]. In this study, every isolate except JAK3 could withstand the series of stress and was capable of adapting to the extreme conditions (Table 2). These isolates, thus, could be potential leavening agent in bread making.

In response to temperature change, all the strains including commercial yeast strain were able to grow at temperatures $25^{\circ} \mathrm{C}, 30^{\circ} \mathrm{C}$, and $37^{\circ} \mathrm{C}$. Strains JAK3 and SUGW showed feeble growth at $37^{\circ} \mathrm{C}$. However, the strain SUG1 was able to survive at higher temperature $\left(45^{\circ} \mathrm{C}\right)$ too at which even the commercial strain failed to grow (Table 3 ). It indicated that they could have better potential in bread making to speed up the proofing process, with increased carbon dioxide production [41].

In sugar utilization test, change of color to yellow signifies that the organisms utilize sugar to produce acidic products and gas which is trapped in Durham tubes. The orange color indicates the partial fermentation of sugars. All the isolates were able to ferment sugars to different extent (Table 4). However, the three strains MUR3B, ENG, SUG1, and DPSW showed sugar utilization capability comparable to the commercial strain, that is, DY5. MUR3B showed maximum gas production in all the sugars. This strain produced maximum gas in fructose compared to DY5. Since gas production is the most important criteria for leavening and can indicate the high invertase activity, strains can be selected on the basis of gas production too [36].

In baking process, it is very important for a yeast strain to survive the minimal osmotic pressure [22]. Osmotic pressure of the medium is vital in determining the cell viability [24]. During osmotic stress, cell dies due to several reasons such as water efflux across the membrane [42], removal of water molecules causing structural modifications of phospholipids [43], osmotic mass transfer [44], and toxicity caused by high solutes concentration [45]. The one-way between-groups analysis was performed to observe the effect of high glucose concentration which corresponds to osmotic pressure on growth of different yeast species, as measured by cell density. Yeast strains were cultured at three different glucose concentrations $(30 \%, 40 \%$, and $50 \%)$ and the growth of the strains at 
TABLE 2: Stress exclusion tests on yeast cell for temperature and cell osmotic pressure in high concentration of ethanol and sugar.

\begin{tabular}{|c|c|c|c|c|c|c|}
\hline \multirow[b]{2}{*}{ Samples } & \multicolumn{5}{|c|}{ Growth into different media } & \multirow[b]{2}{*}{$\begin{array}{l}\text { Use of yeast as potential } \\
\text { leavening agent }\end{array}$} \\
\hline & YPG & Temperature $37^{\circ} \mathrm{C}$ & Ethanol 8\% (v/v) & $\begin{array}{l}\text { YPG 20\% (v/v) } \\
\text { glucose }\end{array}$ & $\begin{array}{c}\text { YPS 2\% (v/v) sucrose + } \\
\text { ethanol } 8 \%(\mathrm{v} / \mathrm{v})\end{array}$ & \\
\hline MUR3B & +++ & +++ & +++ & +++ & ++ & Yes \\
\hline ENG & +++ & ++ & +++ & +++ & ++ & Yes \\
\hline DPSW & +++ & +++ & +++ & ++ & ++ & Yes \\
\hline FAPW & +++ & +++ & +++ & +++ & ++ & Yes \\
\hline DY5 (SC) & +++ & +++ & +++ & +++ & ++ & Yes \\
\hline SUG1 & +++ & +++ & +++ & +++ & ++ & Yes \\
\hline JAK3 & +++ & ++ & +++ & -- & -- & No \\
\hline SUGW & +++ & +++ & ++ & ++ & ++ & Yes \\
\hline
\end{tabular}

+++: intensive response; ++: moderate response; --: no response; YPG: yeast peptone glucose medium; YPS: yeast peptone sucrose medium.

TABLE 3: Growth and inhibition of yeast isolates at different growth temperatures.

\begin{tabular}{|c|c|c|c|c|c|}
\hline \multirow{2}{*}{ S. number } & \multirow{2}{*}{ Samples } & \multicolumn{4}{|c|}{ Temperature } \\
\hline & & $25^{\circ} \mathrm{C}$ & $30^{\circ} \mathrm{C}$ & $37^{\circ} \mathrm{C}$ & $45^{\circ} \mathrm{C}$ \\
\hline (1) & MUR3B & +++ & +++ & +++ & -- \\
\hline (2) & ENG & +++ & +++ & +++ & -- \\
\hline (3) & DPSW & +++ & +++ & ++ & -- \\
\hline (4) & FAPW & +++ & +++ & +++ & -- \\
\hline (5) & DY5 (SC) & +++ & +++ & +++ & -- \\
\hline (6) & SUG1 & +++ & +++ & +++ & ++ \\
\hline (7) & JAK3 & +++ & ++ & ++ & -- \\
\hline (8) & SUGW & +++ & +++ & ++ & -- \\
\hline
\end{tabular}

+++ : intensive response; ++: moderate response; --: no response.

these concentrations was compared to that with commercial strains DY5. There was a statistically significant difference at the $P<0.02$ level in cell density for the three glucose concentrations: $30 \%, 40 \%$, and $50 \%$ glucose concentration (Figure 2(a))

The effective size, calculated using eta squared, was 0.917 for $30 \%, 0.909$ for $40 \%$, and 0.883 for $50 \%$ glucose concentration. Post hoc comparisons using Tukey's HSD test indicated that the mean cell density for DPSW in both $30 \%$ and $40 \%$ glucose concentration was significantly lower than that of DY5. The mean cell density of other strains did not differ significantly compared to that of commercial dry yeast (DY5) in the three given glucose concentrations. There was significant decrease to the biomass of all strains in $50 \%$ glucose concentration with respect to the biomass of respective strains at $40 \%$. In $30 \%$ and $40 \%$, glucose concentration MUR3B and ENG shows the same level of tolerance to that of DY5. This means they can tolerate a higher osmotic pressure than the other strains including commercial yeasts.

The one-way between-groups analysis was performed to observe the alcohol tolerance of different yeast strains, as measured by cell density in presence of different alcohol concentrations (Figure 2(b)). It is necessary to check the tolerability and viability of yeast strains at different alcohol concentrations because alcohol is produced as a secondary metabolite that increases the flavor of bread during leavening
[46]. Yeast strains were cultured at three different alcohol concentrations $(10 \%, 13 \%$, and $15 \%)$. At $10 \%$ alcohol concentration, the strains MUR3B and ENG showed tolerance to alcohol that was comparable to DY5. The strain ENG that was isolated from grapes showed a better cell growth than commercial yeast, that is, DY5. However, the post hoc comparisons indicated that the mean cell density for DPSW and SUG1 in $10 \%$ alcohol concentration was significantly lower than that of DY5. Similarly, at $13 \%$ alcohol concentration, the strain MUR3B and ENG showed better tolerance to alcohol compared to DY5 but the mean cell density for DPSW and SUG1 was significantly lower than that of DY5 at $13 \%$ alcohol concentration too. ENG and MUR3B showed ethanol tolerance that is comparable to DY5. Some level of growth was seen at $15 \%$ alcohol concentration also but the biomass production was significantly lower than that of $13 \%$. So these strains showed some level of alcohol tolerance at $15 \%$ and are tolerant to $13 \%$ [47]. Ethanol damages the mitochondrial DNA and causes the inactivation of enzymes such as hexokinases and dehydrogenase and if the alcohol concentration is too high, it destroys the cell membranes of yeast and kills them by impairing their growth [48].

The growth of different strains was checked in glucose and sucrose by measuring the cell density (Figure 3). In glucose, the cell density of MUR3B, ENG, and SUG1 was very similar to the cell density of commercial strain DY5. However, the growth of DPSW was very low compared to DY5. In sucrose, 
TABLE 4: Sugar utilization test.

\begin{tabular}{llccccccrrrr}
\hline \multirow{2}{*}{ Yeast strains } & \multicolumn{2}{c}{ Dextrose } & \multicolumn{2}{c}{ Fructose } & \multicolumn{2}{c}{ Galactose } & \multicolumn{3}{c}{ Maltose } & \multicolumn{2}{c}{ Sucrose } \\
& Color & Gas & Color & Gas & Color & Gas & Color & Gas & Color & Gas \\
\hline DY5 & Yellow & +++ & Yellow & ++ & Yellow & ++ & Yellow & +++ & Yellow & +++ \\
DPSW & Yellow & +++ & Orange & ++ & Yellow & ++ & Yellow & ++ & Yellow & +++ \\
MUR3B & Yellow & +++ & Yellow & +++ & Yellow & +++ & Yellow & +++ & Yellow & +++ \\
ENG & Yellow & ++ & Yellow & ++ & Yellow & + & Orange & ++ & Yellow & +++ \\
SUG1 & Yellow & ++ & Yellow & +++ & Yellow & ++ & Yellow & +++ & Yellow & +++ \\
FAPW & Orange & + & Orange & - & Orange & ++ & Orange & ++ & Yellow & - \\
JAK3 & Orange & - & Orange & + & Yellow & +++ & Yellow & + & Orange & + \\
SUGW & Yellow & ++ & Orange & + & Orange & - & Yellow & +++ & Yellow & ++ \\
\hline
\end{tabular}

+: $\leq$ one-third of Durham tube; ++: greater than one-third and $\leq$ two-thirds of Durham tube; +++: greater than two-thirds; -: no gas production.

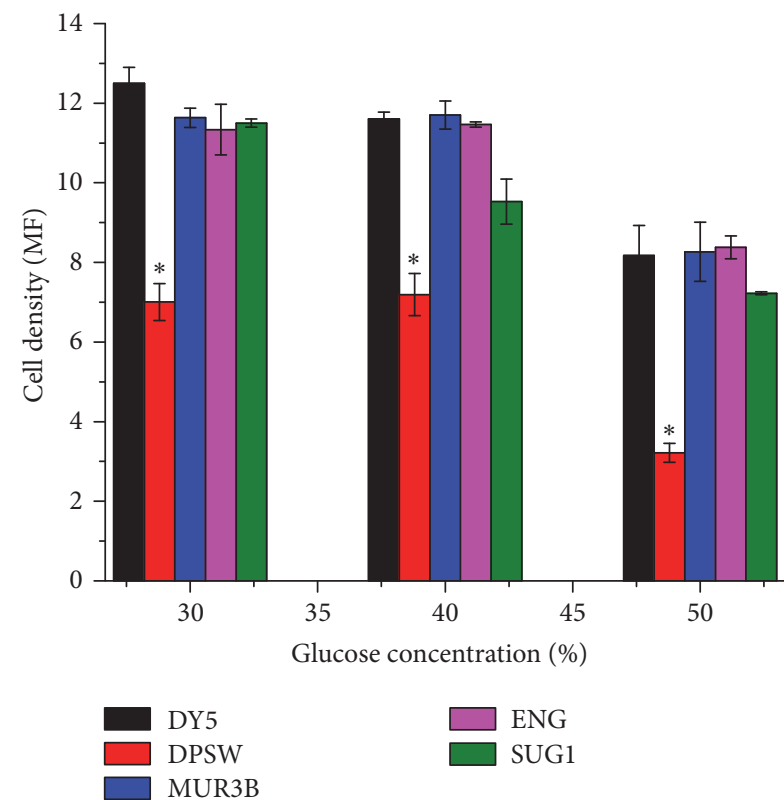

(a)
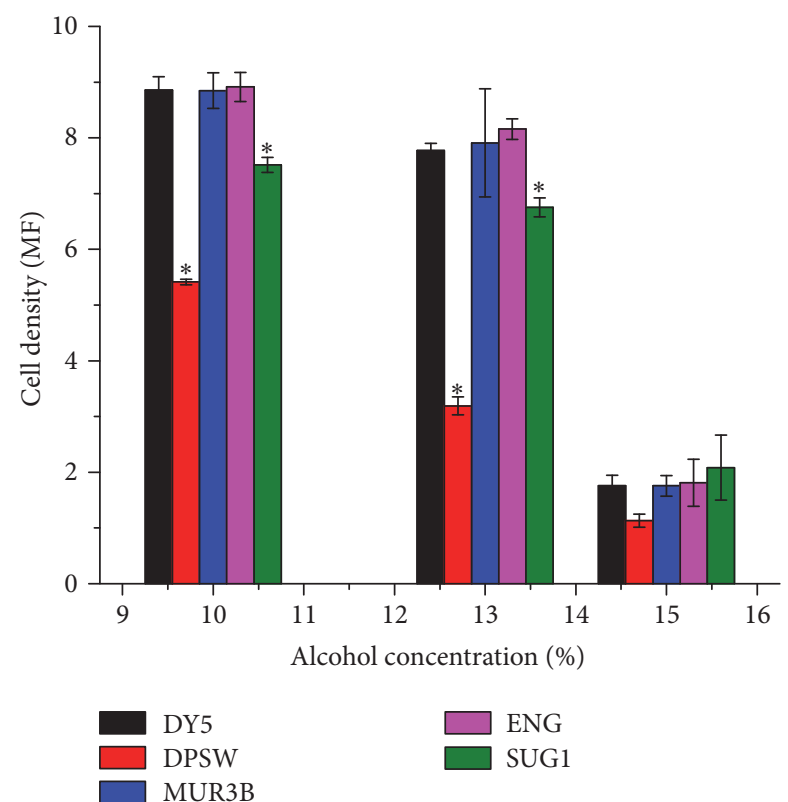

MUR3B

Figure 2: Comparison of osmotolerance (a) and alcohol tolerance (b) of different yeast isolates with commercial yeast. ${ }^{*}$ The mean difference is significant at 0.02 level when comparing means between DY5 and other strains.

only the cell density of ENG was very similar to DY5. Other strains showed less growth compared to commercial strain.

The invertase activity for the strain MUR3B was found to be the highest (Figure 4(a)). The activity of the other strains including commercial yeast was significantly lower than that of MUR3B. The strains having high level of invertase activities have found to be less capable of overcoming osmotic pressure [22] but the MUR3B strain that exhibits highest level of invertase activity also shows growth comparable to commercial strain at highest concentration of glucose in osmotic test. One unit of invertase is defined as amount of enzyme which liberates one mole of glucose $/ \mathrm{minute} / \mathrm{mL}$ under the assay condition (optimal pH (4.8), temperature $\left(40^{\circ} \mathrm{C}\right)$, and initial sucrose concentrations of $\left.5 \mathrm{mM}\right)$.

\section{Dough Fermentation and Baking}

The rise of dough level or the speed of fermentation process was assessed by noting the rise of dough mixture kept in measuring cylinder (Figure 5). Although the rise in DY5 was the fastest, the strains ENG and MUR3B showed similar rise. Since the strain DPSW showed poor performance in ethanol tolerability, cell density, and hyperosmotic tolerance, it was not used in dough making process.

The final fermented dough with SUG1 and ENG was comparable to that by the commercial strain DY5. The crosssectional examination of the dough from all strains also showed similar crumb textural property (Figure 6). The properties of the baked dough from the three strains SUG1, MUR3B, and ENG were found similar to the dough fermented by the commercial yeast strain (DY5) (Table 5).

\section{Conclusion}

This study showed that three isolated strains of S. cerevisiae from native sources could be used as a commercial baker's yeast. The three strains, all being Saccharomyces cerevisiae, 


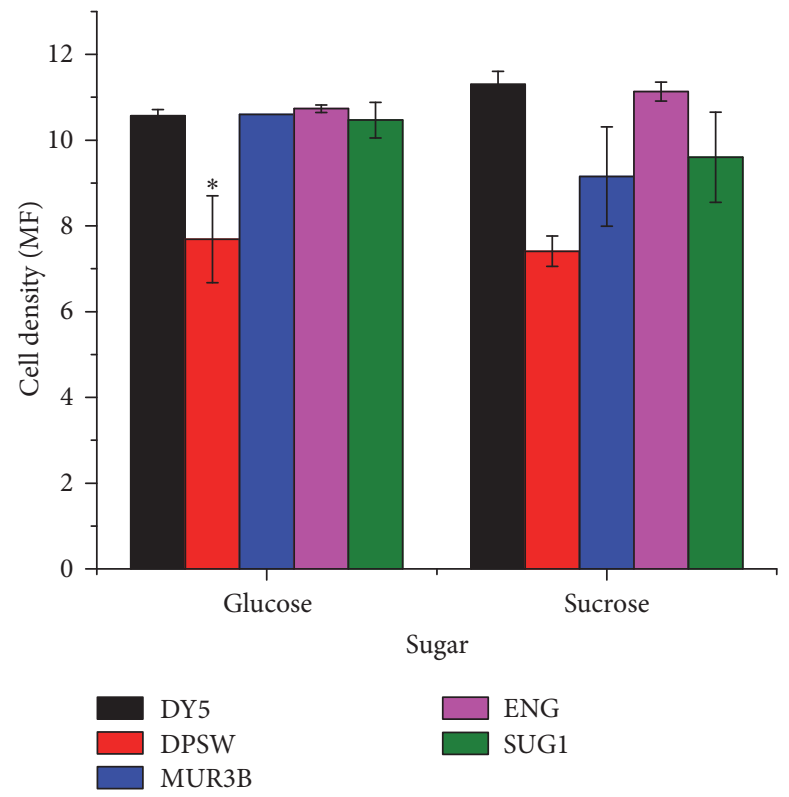

FIGURE 3: Comparison of different yeast isolates with commercial yeast in presence of sugar. Cell density comparison of different yeast isolates with commercial yeast in presence of glucose and sucrose. ${ }^{*}$ The mean difference is significant at 0.02 level when comparing means between DY5 and other strains.

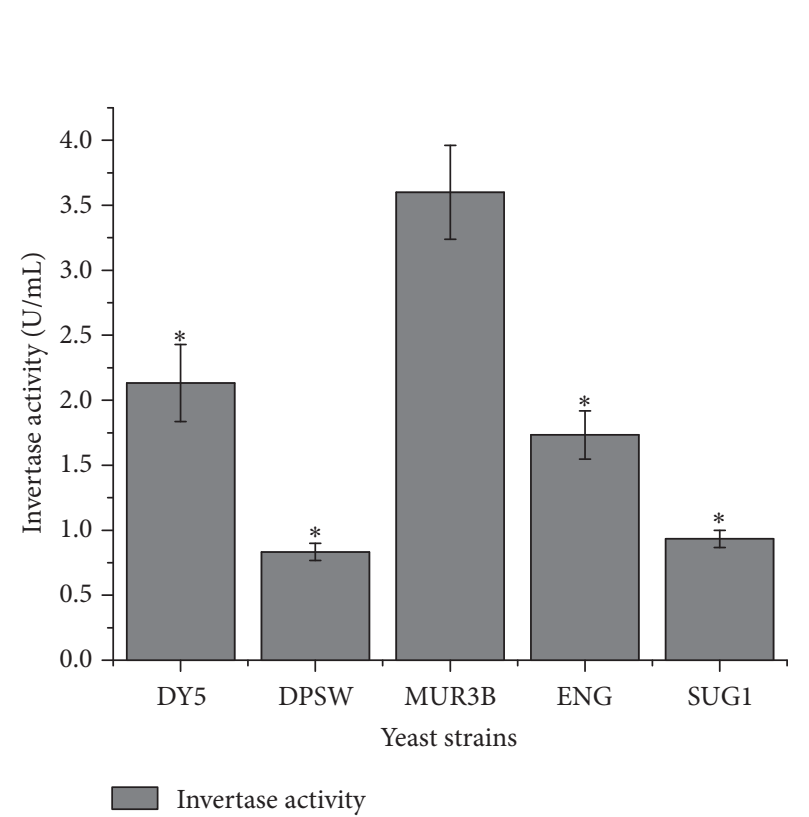

(a)

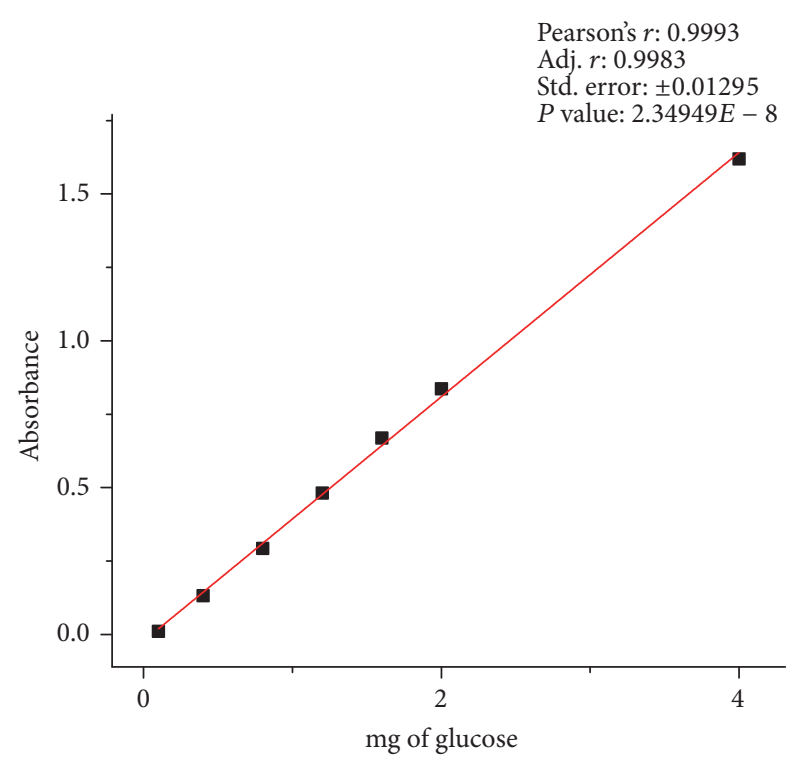

(b)

FIGURE 4: (a) Invertase activity of different yeast strains; (b) standard curve of mg of glucose versus absorbance. ${ }^{*}$ The mean difference is significant at 0.02 level when comparing means between MUR3B and other strains.

are MUR3B from Murcha, ENG from grapes, and SUG1 from sugarcane; they show strong potential for commercialization after appropriate research on biomass optimization culture preservation. These strains can give unique flavor to bread and can form an identity for the bread industry of Nepal. Our study finds that the indigenous plant "Dar" inhabits yeast, but this yeast strain could not be used as baker's yeast because of its poor leavening properties. Meanwhile, the strains from Murcha, grapes, and sugarcane are potential sources for baker's yeast.

\section{Conflicts of Interest}

The authors declare that there are no conflicts of interest regarding the publication of this paper. Also the funding 


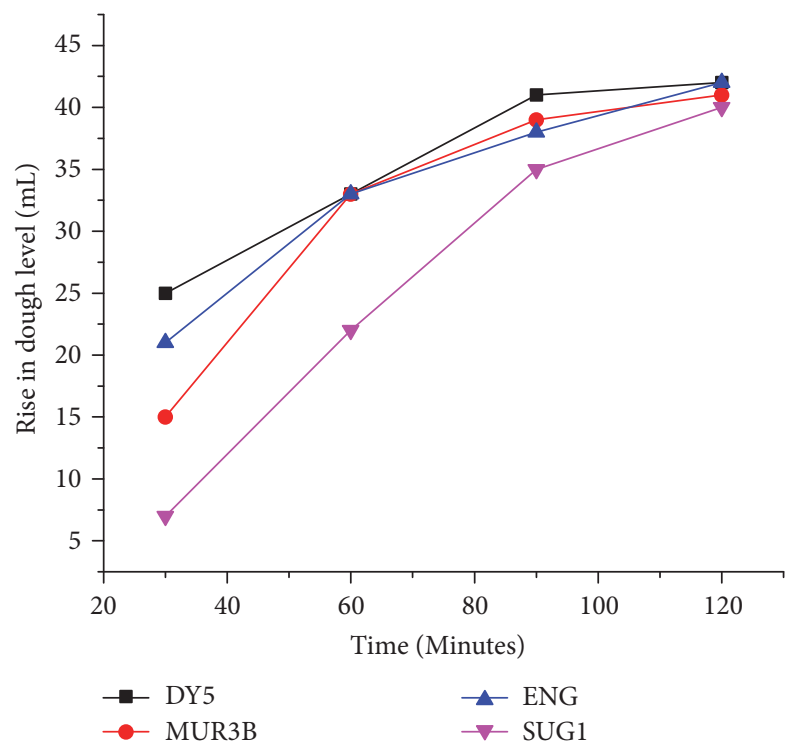

FIGURE 5: Comparison of leavening effect of different yeast strains.
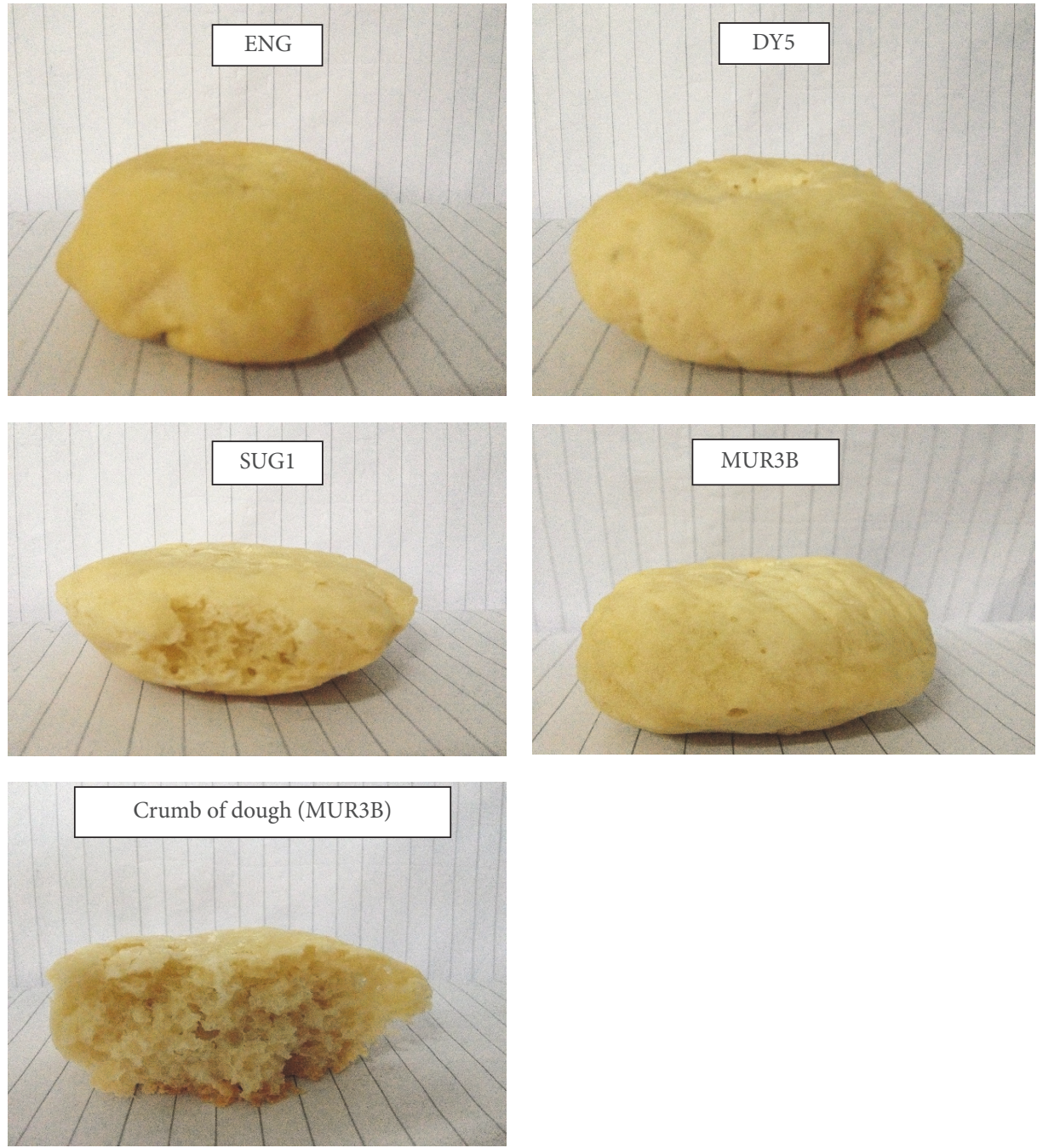

FIGURE 6: Baked dough from different isolated strains: SUG1, MUR3B, ENG, and DY5. 
TABLE 5: Properties of baked dough.

\begin{tabular}{lcccc}
\hline S. number & Sample & Color of crust & Color of crumb & Aroma \\
\hline$(1)$ & MUR3B & Light Brown & Creamy & +++ \\
$(2)$ & ENG & Light Brown & Creamy & ++ \\
$(3)$ & DY5 & Light Brown & Creamy & +++ \\
$(4)$ & SUG1 & Light Brown & Creamy & +++ \\
\hline
\end{tabular}

+++ : baking aroma of commercial active dry yeast; ++: intensity of aroma being less than that of commercial active dry yeast.

body mentioned in Acknowledgments does not lead to any conflicts of interest regarding the publication of this paper.

\section{Acknowledgments}

The authors thankfully acknowledge Kyushu University Research Grant for funding the research project on "Fermented Foods of Nepal" and Department of Biotechnology, Kathmandu University, for providing research space. They are grateful to Ms. Asmita Shrestha and Mr. Sandeep Adhikari of Department of Biotechnology, Kathmandu University, for their support during the research and documentation. They are thankful to Mr. Himal Shrestha and Mr. Aman Maharjan of Department of Natural Science, Kathmandu University, for their support in data analysis.

\section{References}

[1] H. J. Phaí, M. W. Miller, and E. M. Mark, "Industrial uses of yeast," in The Life of Yeast, pp. 238-266, Harvard University Press, Cambridge, Mass, USA, 2nd edition, 1978.

[2] P. Gélinas, "In search of perfect growth media for Baker's yeast production: Mapping patents," Comprehensive Reviews in Food Science and Food Safety, vol. 11, no. 1, pp. 13-33, 2012.

[3] I. S. Pretorius, "Tailoring wine yeast for the new millennium: Novel approaches to the ancient art of winemaking," Yeast, vol. 16, no. 8, pp. 675-729, 2000.

[4] B. J. Viljoen and G. M. Heard, "Saccharomyces cerevisiae," in Encylopedia of Food Microbiology, R. K. Robinson, C. A. Batt, and P. D. Patel, Eds., pp. 1918-1924, Academic Press, 2000.

[5] I. H. Cho and D. G. Peterson, "Chemistry of bread aroma: A review," Food Science and Biotechnology, vol. 19, no. 3, pp. 575$582,2010$.

[6] Y. Fleury Rey, R. Bel-Rhlid, and M.-A. Juillerat, "Biogeneration of 2-(1-hydroxyethyl)-4,5-dihydrothiazole as precursor of roasted and popcorn-like aroma for bakery products," Journal of Molecular Catalysis B: Enzymatic, vol. 19-20, pp. 473-477, 2002.

[7] K. Poutanen, L. Flander, and K. Katina, "Sourdough and cereal fermentation in a nutritional perspective," Food Microbiology, vol. 26, no. 7, pp. 693-699, 2009.

[8] J. F. Spencer and D. M. Spencer, Yeasts in Natural and Artificial Habitats, Springer-Verlag, Berlin, Germany, 1997, P. 381.

[9] C. R. Arias, J. K. Burns, L. M. Friedrich, R. M. Goodrich, and M. E. Parish, "Yeast species associated with orange juice: evaluation of different identification methods," Applied and Environmental Microbiology, vol. 68, no. 4, pp. 1955-1961, 2002.

[10] S. R. Ceccato-Antonini, C. D. Tosta, and A. C. Da Silva, "Determination of yeast killer activity in fermenting sugarcane juice using selected ethanol-making strains," Brazilian Archives of Biology and Technology, vol. 47, no. 1, pp. 13-23, 2004.

[11] Trade and Export Promotion Centre, "Export Import Data Bank Version 1.5," 2013, http://www.efourcore.com.np/tepcdatabank.

[12] T. J. Ekunsanmi and S. A. Odunfa, "Ethanol tolerance, sugar tolerance and invertase activities of some yeast strains isolated from steep water of fermenting cassava tubers," Journal of Applied Bacteriology, vol. 69, no. 5, pp. 672-675, 1990.

[13] C. Leão and N. Van Uden, "Effects of ethanol and other alkanols on passive proton influx in the yeast Saccharomyces cerevisiae," BBA - Biomembranes, vol. 774, no. 1, pp. 43-48, 1984.

[14] Jadibuti Association of Nepal, 1995, http://www.forestrynepal .org/resources/trees/boehmeria-rugulosa.

[15] A. Kumar, "Boehmeriarugulosa," 20141, http://www.flowersofindia.net/catalog/slides/Daar.html.

[16] P. A. Kamal and A. Rajendra, "Eating from the wild: indigenous knowledge on wild edible plants in parrohavdc of rupandehi district, central nepal," International Journal of Social Forestry, vol. 3, no. 1, pp. 28-48, 2010.

[17] J. P. Sampaio and P. Gonçalves, "Natural populations of Saccharomyces kudriavzevii in Portugal are associated with Oak bark and are sympatric with S. cerevisiae and S. paradoxus," Applied and Environmental Microbiology, vol. 74, no. 7, pp. 2144-2152, 2008.

[18] J. B. KC, D. K. Subba, and B. K. Rai, "Plants used in Murcha Preparation in Eastern Nepal," Journal of Hill Research Sikkim Science Society, vol. 14, no. 2, pp. 107-109, 2001.

[19] N. Tsuyoshi, R. Fudou, S. Yamanaka et al., "Identification of yeast strains isolated from marcha in Sikkim, a microbial starter for amylolytic fermentation," International Journal of Food Microbiology, vol. 99, no. 2, pp. 135-146, 2005.

[20] B. K. Rai and D. K. Subba, "Screening of fermentative yeasts from murcha plants and assessment of their brewing value," Journal of Food Science and Technology, vol. 40, no. 4, pp. 382385, 2003.

[21] J. P. Tamang and P. K. Sarkar, "Microflora of murcha: an amylolytic fermentation starter.," Microbios, vol. 81, no. 327, pp. 115-122, 1995.

[22] A. G. Maruf et al., "Leavening Ability of Yeast Isolated from Different Local Fruits in Bakery Product," International Food Research journal, vol. 40, no. 12, pp. 1413-1419, 2011, Universiti Putra Malaysia.

[23] S. S. Matapathi, A. B. Patil, P. Jones Nirmalnath et al., "Isolation and screening of efficient yeast strains for wine making," Karnataka Journal of Agricultural Sciences, vol. 17, no. 4, pp. 435439, 2004.

[24] F. Randez-Gil, I. Córcoles-Sáez, and J. A. Prieto, "Genetic and phenotypic characteristics of baker's yeast: relevance to baking," Annual Review of Food Science and Technology, vol. 4, no. 1, pp. 191-214, 2013.

[25] D. J. Ederer and G. M. Ederer, andG.M.Ederer.1975.Principles of biochemical tests in diagnostic microbiology, John Wiley and Sons, New York, NY, USA, 1975, 79-82.

[26] R. T. Morrison and R. N. Boyd, Diazonium Salts, Organic Chemistry, Allyn and Bacon Inc, Boston, Mass, USA, 1959, 570584.

[27] J. G. Rhodes and G. D. Roberts, "Comparison of four methods for determining nitrate utilization by cryptococc," Journal of Clinical Microbiology, vol. 1, pp. 9-10, 1974. 
[28] R. M. Atlas and L. C. Parks, Handbook of microbiological media, CRC Press, New York, NY, USA, 1996, P. 1562.

[29] M. Thais, T. M. Guimarães, D. G. Moriel, I. P. Machado, C. M. T. F. Picheth, and T. M. B. Bonfim, "Isolation and characterization of Saccharomyces cerevisiae strains of winery interest," Brazilian Journal of Pharmaceutical and Sciences, vol. 42, no. 1, pp. 119-126, 2006.

[30] B.-I. Ono, N. Ishii, S. Fujino, and I. Aoyama, "Role of hydrosulfide ions (HS-) in methylmercury resistance in Saccharomyces cerevisiae," Applied and Environmental Microbiology, vol. 57, no. 11, pp. 3183-3186, 1991.

[31] J. B. Sumner and S. F. Howell, "A method for determination of saccharase activity," The Journal of Biological Chemistry, vol. 108, pp. 51-54, 1935.

[32] T. M. El-Nemr, "Immobilization of recombinant strains of Saccharomyces cerevisiae for the hydrolysis of lactose in salted Domiati cheese whey," European Food Research and Technology, vol. 212, no. 2, pp. 225-227, 2001.

[33] Dakotayeast, "History of yeast," 1989, http://www.dakotayeast .com/yeast_history.html.

[34] M. W. Graeme and A. W. Nia, Introduction to Fungal Physiology, K. Kevin, Ed., Fungi: Biology and Application, John Wiley and Sons, Ltd, 2005, 1-34.

[35] J. S. Hough, D. E. Briggs, and R. Stevens, "Metabolism of wort by yeast," in Malting and Brewing Science, J. S. Hough, D. E. Briggs, and R. Stevens, Eds., pp. 441-479, Chapman and Hall Ltd, London. UK, 1971.

[36] K. J. Verstrepen, G. Derdelinckx, H. Verachtert et al., "Yeast flocculation: what brewers should know," Applied Microbiology and Biotechnology, vol. 61, no. 3, pp. 197-205, 2003.

[37] M. Stratford, "Lectin-mediated aggregation of yeasts - Yeast flocculation," Biotechnology \& Genetic Engineering Reviews, vol. 10, no. 1, pp. 283-341, 1992.

[38] P. A. Henschke and T. H. Lee, "Application of Biotechnology to the improvement of wine yeast," in Proceedings of the international standard for the labelling of wines, vol. 1, pp. 1-11, 1994.

[39] C. Ivorra, J. E. Pérez-Ortín, and M. L. Del Olmo, "An inverse correlation between stress resistance and stuck fermentations in wine yeasts. A molecular study," Biotechnology and Bioengineering, vol. 64, no. 6, pp. 698-708, 1999.

[40] A. Querol, M. T. Fernández-Espinar, M. Del Olmo, and E. Barrio, "Adaptive evolution of wine yeast," International Journal of Food Microbiology, vol. 86, no. 1-2, pp. 3-10, 2003.

[41] C. Pataro, A. Santos, S. R. Correa, P. B. Morais, V. R. Linardi, and C. A. Rosa, "Physiological characterization of yeasts isolated from artisanal fermentation in an Aguardente distillery," Brazilian Journal of Microbiology, vol. 29, no. 2, pp. 104-108, 1998.

[42] A. A. Esener, G. Bol, N. W. F. Kossen, and J. A. Roels, "Effect of water activity on microbial growth," Biotechnology Advances, vol. 3, pp. 339-344, 1980.

[43] K. Muldrew and L. E. McGann, "The osmotic rupture hypothesis of intracellular freezing injury," Biophysical Journal, vol. 66, no. 2 I, pp. 532-541, 1994.

[44] D. Billi and M. Potts, "Life and death of dried prokaryotes," Research in Microbiology, vol. 153, no. 1, pp. 7-12, 2002.

[45] Y. Mille, J.-P. Obert, L. Beney, and P. Gervais, "New drying process for lactic bacteria based on their dehydration behavior in liquid medium," Biotechnology and Bioengineering, vol. 88, no. 1, pp. 71-76, 2004.
[46] R. Gaxiola, I. F. De Larrinoa, J. M. Villalba, and R. Serrano, "A novel and conserved salt-induced protein is an important determinant of salt tolerance in yeast," EMBO Journal, vol. 11, no. 9, pp. 3157-3164, 1992.

[47] Z. Noroul Asyikeen, A. G. Ma’aruf, A. M. Sahilah, A. Mohd Khan, and W. M. Wan Aida, "A new source of Saccharomyces cerevisiae as a leavening agent in bread making," International Food Research Journal, vol. 20, no. 2, pp. 967-973, 2013.

[48] J. I. Ibeas and J. Jimenez, "Mitochondrial DNA loss caused by ethanol in Saccharomyces cerevisiae flour yeasts," Appl. Environ Microbiol, vol. 36, pp. 7-12, 1997. 

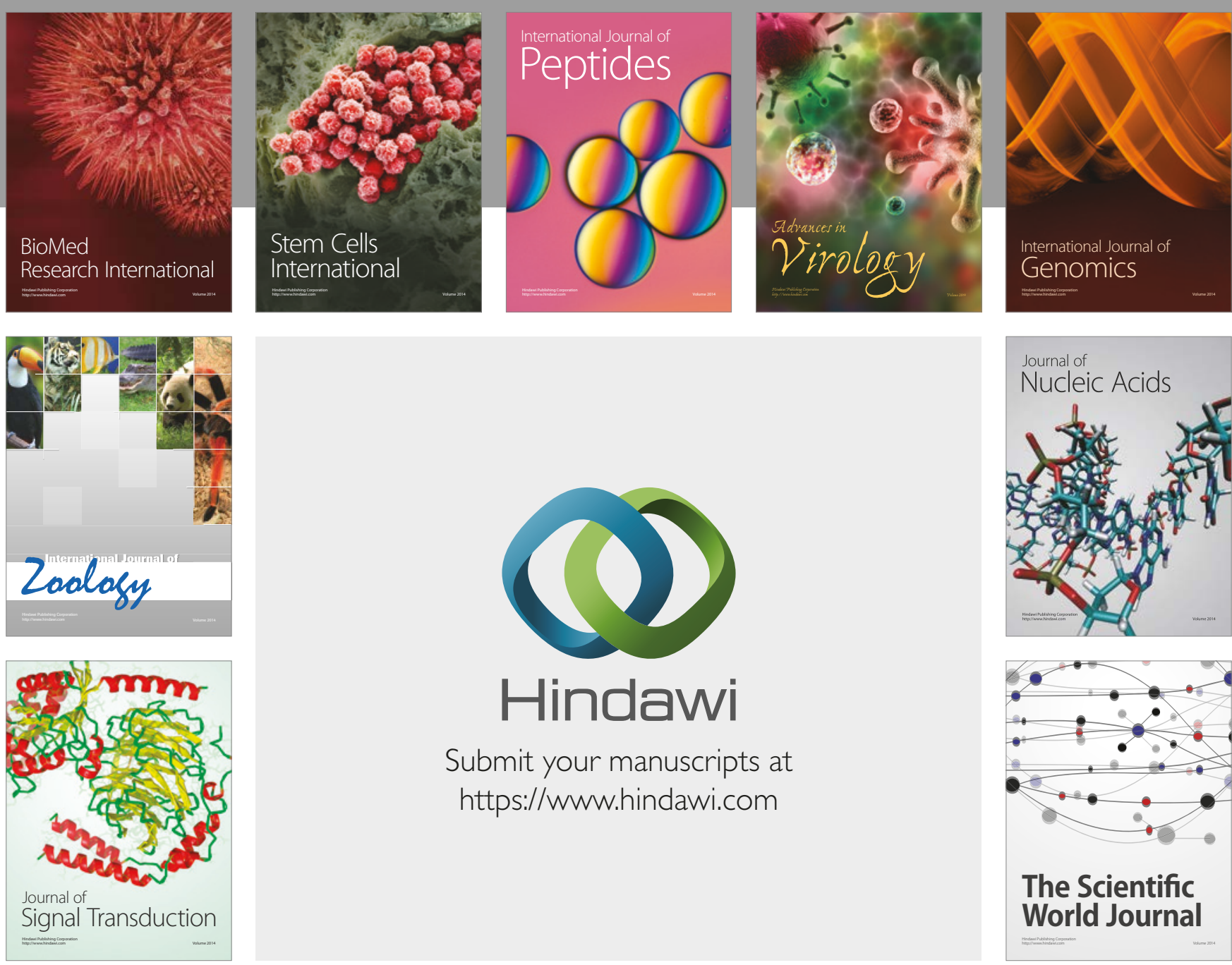

Submit your manuscripts at

https://www.hindawi.com
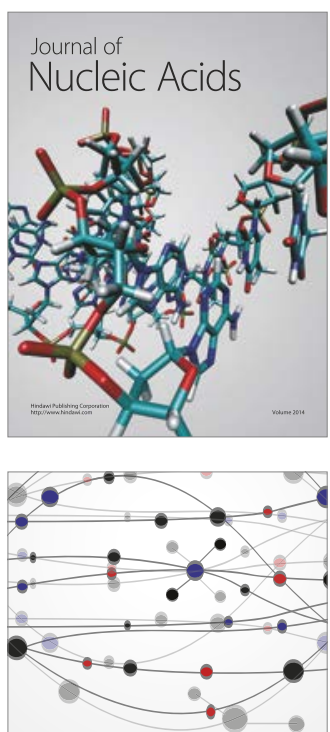

The Scientific World Journal

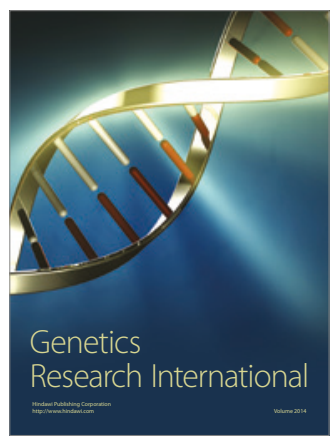

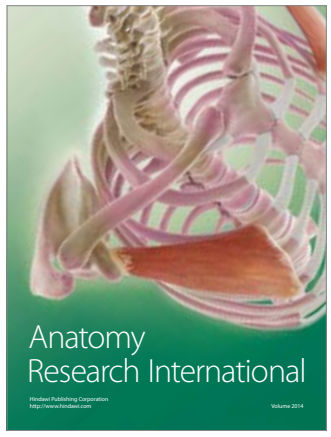

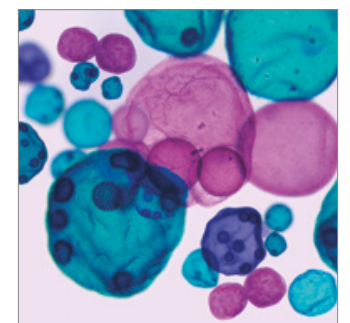

International Journal of Microbiology
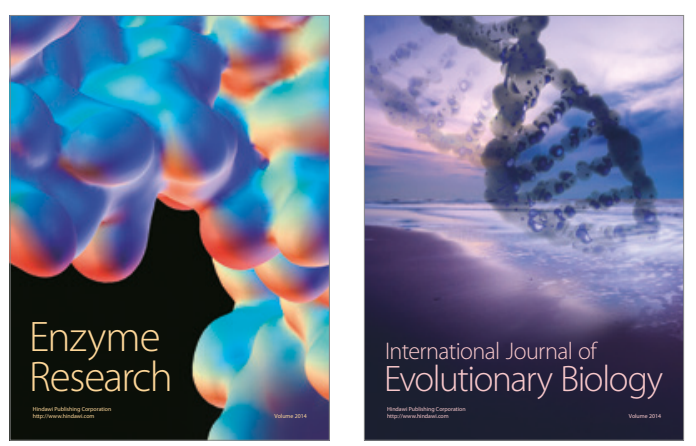
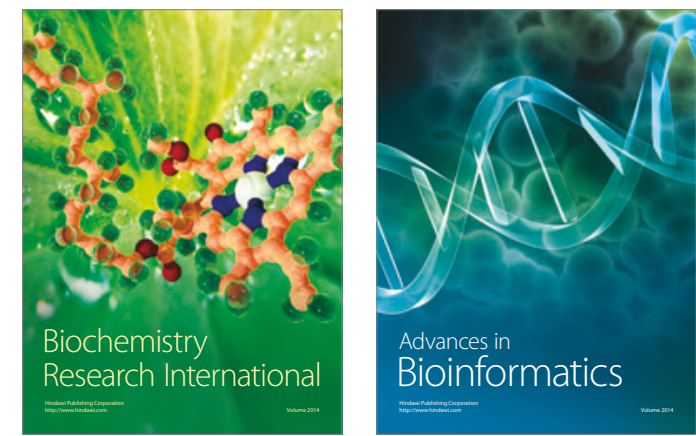

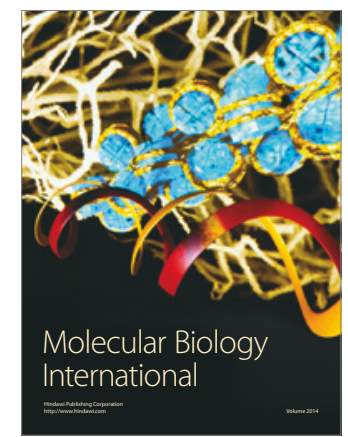

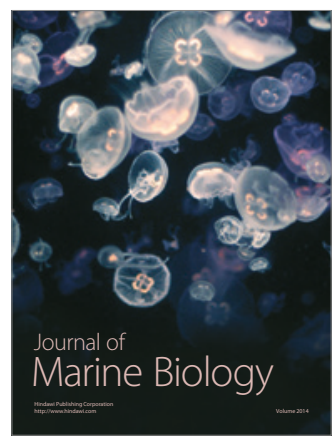

